Fixed Point Theory, 21(2020), No. 2, 441-452

DOI: $10.24193 /$ fpt-ro.2020.2.31

http://www.math.ubbcluj.ro/ nodeacj/sfptcj.html

\title{
A STRONG CONVERGENCE THEOREM FOR AN INERTIAL ALGORITHM FOR A COUNTABLE FAMILY OF GENERALIZED NONEXPANSIVE MAPS
}

\author{
C.E. CHIDUME* AND M.O. NNAKWE** \\ *African University of Science and Technology, Abuja, Nigeria \\ E-mail: cchidume@aust.edu.ng \\ **African University of Science and Technology, Abuja, Nigeria \\ E-mail: mondaynnakwe@gmail.com
}

\begin{abstract}
Let $E$ be a uniformly smooth and strictly convex real Banach space with dual space, $E^{*}$. In this paper, we present a Krasnoselkii-type inertial algorithm and prove a strong convergence theorem for approximating a common fixed point for a countable family of generalized nonexpansive maps. Furthermore, we apply our theorem and prove a strong convergence theorem for approximating a common fixed point for a countable family of generalized- $J$-nonexpansive maps. Our theorem is an improvement of the results of Klin-earn et al. (Taiwanese J. of Maths. Vol. 16, No. 6, pp. 1971-1989, Dec. 2012), Chidume et al. (Advances in Fixed Point Theory, Vol. 7, No. 3 (2017), 413-431) and Dong et al. (Optimization Letters, 2017, DOI: 10.1007/s11590-016-1102-9). Finally, we give a numerical experiment to illustrate the efficiency and advantage of the inertial algorithm over an algorithm without inertial term.
\end{abstract}

Key Words and Phrases: Generalized nonexpansive maps, NST-condition, inertial term, fixed point.

2010 Mathematics Subject Classification: 47H09, 47H10, 47J25, 47J05.

Research supported from ACBF Research Grant Funds to AUST.

\section{REFERENCES}

[1] Y. Alber, Metric and generalized projection operators in Banach spaces: properties and applications, Theory and Applications of Nonlinear Operators of Accretive and Monotone Type (A.G. Kartsatos, Ed.), Marcel Dekker, New York, 1996, 15-50.

[2] Y. Alber, I. Ryazantseva, Nonlinear Ill Posed problems of Monotone Type, Springer, London, UK, 2006.

[3] R.I. Bot, E.R. Csetnek, A hybrid proximal-extragradient algorithm with inertial effects, Numer. Funct. Anal. Optim., 36(2015), 951-963.

[4] S.S. Chang, H.W. Joseph Lee, C.K. Chan, W.B. Zhang, A modified halpern-type iteration algorithm for totally quasi- $\phi$-asymptotically nonexpansive mappings with applications, Applied Mathematics and Computation, 218(2012), 6489-6497.

[5] C.E. Chidume, K.O. Idu, Approximation of zeros of bounded maximal monotone maps, solutions of Hammerstein integral equations and convex minimization problemss, Fixed Point Theory and Applications, 97(2016), DOI: 10.1186/s13663-016-0582-8. 
[6] C.E. Chidume, E.E. Otubo, C.G. Ezea, Strong convergence theorem for a common fixed point of an infinite family of J-nonexpansive maps with applications, The Australian Journal of Mathematical Analysis and Applications, 13(2016), no. 1, 1-13.

[7] C.E. Chidume, E.E. Otubo, C.G. Ezea, M.O. Uba, A new monotone hybrid algorithm for a convex feasibility problem for an infinite family of nonexpansive-type maps, with applications, Advances in Fixed Point Theory, 7(2017), no. 3, 413-431.

[8] C.E. Chidume, O.M. Romanus, U.V. Nnyaba, Strong convergence theorems for a common zero of an infinite family of gamma-inverse strongly monotone maps with applications, The Australian Journal of Mathematical Analysis and Applications, 14(2017), no. 1, 1-11.

[9] C.E. Chidume, M.O. Uba, M.I. Uzochukwu, E.E. Otubo, K.O. Idu, A strong convergence theorem for zeros of maximal monotone maps with applications to convex minimization and variational inequality problems, Proc. Edinburgh Math. Soc. (accepted, January 2018).

[10] I. Cioranescu, Geometry of Banach Spaces, Duality Mappings and Nonlinear Problems, Kluwer Academic Publisher, 62, 1990.

[11] Q.L. Dong, H.B. Yuan, C.Y. Je, T.M. Rassias, Modified inertial Mann algorithm and inertial CQ-algorithm for nonexpansive mappings, Optimization Lett., 2017, DOI: 10.1007/s11590-0161102-9.

[12] T. Ibaraki, W. Takahashi, A new projection and convergence theorems for the projections in Banach spaces, J. Approx. Theory, 149(2007), 1-14.

[13] C. Klin-earn, S. Suantai, W. Takahashi, Strong convergence theorems by monotone hybrid method for a family of generalized nonexapnsive mappings in Banach spaces, Taiwanese J. Mathematics, 16(2012), no. 6, 1971-1989.

[14] B. Liu, Fixed point of strong duality pseudocontractive mappings and applications, Abstract and Applied Analysis, Vol. 2012, Art. ID 623625, 7 pages, DOI: 10.1155/2012/623625.

[15] B.T. Polyak, Some methods of speeding up the convergence of iteration method, U.S.S.R. Comput. Math. Phy. 4(5), 1-17.

[16] W. Takahashi, Y. Takeuchi, R. Kubota, Strong convergence theorems by hybrid methods for families of nonexpansive mappings in Hilbert spaces, J. Math. Anal. Appl., 341(2008), 276-286.

[17] H. Zegeye, Strong convergence theorems for maximal monotone mappings in Banach spaces, J. Math. Anal. Appl., 343(2008), 663-671.

Received: March 21, 2018; Accepted: June 28, 2018. 